\title{
Penggunaan Metode Simple Additive Weighting (SAW) dalam Pengambilan Keputusan Rekrutmen Karyawan Pada PT. ABC
}

\author{
Implementation of Simple Additive Weighting (SAW) Method in Employee Recruitment
} Decision Making at PT. ABC

Desi Pibriana

Program Studi Sistem Informasi, STMIK Global Informatika MDP

Jl. Rajawali No. 14 Palembang, 30113, Telp (0711) 376400

E-mail: desi.pibriana@mdp.ac.id

\begin{abstract}
Abstrak
Perekrutan pegawai merupakan hal yang penting bagi sebuah perusahaan dalam rangka mendapatkan pegawai baru berkompeten yang sesuai dengan kualifikasi yang telah ditentukan. Seleksi administrasi yang merupakan proses awal dari serangkaian proses rekrutmen pegawai terkadang rentan terhadap unsur subjektifitas, dikarenakan banyaknya berkas yang harus diseleksi dengan cepat, mengingat posisi yang kosong harus segera terisi. Akibatnya, calon pelamar yang direkrut tidak sesuai dengan kualifikasi. Untuk itu, diperlukan model pengambilan keputusan yang dapat digunakan sebagai referensi keputusan oleh bagian Human Resource Development (HRD) sehingga keputusan yang diambil dapat lebih objektif, akurat dan cepat. Salah satu metode yang dapat digunakan dalam pengambilan keputusan adalah Simple Additive Weighting (SAW). Metode ini dipilih karena sangat populer dan sering digunakan untuk pengambilan keputusan yang melibatkan banyak atribut serta membantu pengambil keputusan dalam memilih alternatif terbaik dari sejumlah alternatif yang ada berdasarkan kriteria yang spesifik. Tujuan dari penelitian ini adalah untuk memanfaatkan metode SAW dalam rangka membantu bagian HRD dalam mengambil keputusan dengan lebih objektif terkait rekrutmen karyawan baru. Hasil dari penelitian ini adalah perangkingan terhadap sejumlah alternatif calon karyawan dan mendapatkan hasil berupa daftar calon karyawan yang berhak untuk menempuh proses wawancara yang merupakan rangkaian dari proses rekrutmen karyawan setelah proses seleksi administrasi.
\end{abstract}

Kata kunci: Rekrutmen Pegawai, Seleksi Pegawai, Model Pengambilan Keputusan, Simple Additive Weighting (SAW)

\begin{abstract}
Employee recruitment is an important thing done by the company to get new competent employees that match the predetermined qualifications. The administrative selection which is the initial process of employee recruitment processes is sometimes vulnerable to the subjectivity, due to the large number of files that must be selected quickly, because that vacant position must be filled immediately. This has an impact on newly recruited employees that did not match the qualifications. In this reason, a decision-making model was needed as a reference that can be used by HRD, so that the decisions made can be more objective, accurate and faster. Several methods used in decision making, one of them is Simple Additive Weighting (SAW). This method was chosen because it is prevalent and often used for decision making that involves many attributes and helps decision-makers choose the best alternative from some alternatives based on specific criteria. The purpose of this study is to utilize the SAW method to assist the $H R D$ in making more objective decisions regarding new employee's recruitment. The results of this study are ranked some alternative and get a list of some prospective employees who are entitled to continue the interview after the administrative selection process.
\end{abstract}

Keywords: Employee Recruitment, Employee Selection, Decision Making Models, Simple Additive Weighting (SAW) 


\section{PENDAHULUAN}

Melakukan perekrutan pegawai merupakan hal yang sangat penting bagi sebuah perusahaan, dalam rangka memperoleh calon pegawai baru yang berkompeten untuk menduduki posisi atau jabatan tertentu. Hal ini dilakukan mengingat pegawai dipandang sebagai salah satu aset penting bagi perusahaan dan perlu dikelola serta dikembangkan untuk mendukung kelangsungan hidup dan pencapaian tujuan perusahaan [1].

Seringkali perusahaan menggunakan cara yang subjektif agar posisi yang kosong di perusahaan dapat segera terisi dengan mengabaikan dampaknya dikemudian hari yang disebabkan kesalahan dalam penilaian kompetensi karyawan yang direkrut, terutama pada perusahaan yang tingkat turn over-nya tinggi, seperti PT. ABC yang bergerak dibidang otomotif sebagai main dealer bagi kendaraan roda dua dan sparepart di Kota Palembang. Jika perekrutan karyawan ini dilakukan secara konvensional sementara banyaknya jumlah pegawai yang harus diseleksi serta belum adanya metode standar yang diterapkan perusahaan dalam menyeleksi calon pegawai secara objektif, membuat perusahaan khususnya bagian Human Resource Development (HRD) kesulitan dalam menemukan calon karyawan yang benar-benar kompeten untuk menduduki posisi yang ditawarkan.

Untuk itu, pengelolaan perekrutan karyawan ini harus dilakukan dengan lebih cepat dan hasil yang tetap akurat agar proses bisnis dalam suatu perusahaan dapat berjalan dengan baik [1]. Bagian HRD dapat membuat keputusan objektif terhadap seleksi pegawai, khususnya pada bagian seleksi administrasi dengan lebih cepat dan akurat dengan menerapkan suatu metode dalam pengambilan keputusan untuk menyelesaikannya. Hal ini perlu dilakukan oleh perusahaan agar seleksi administrasi terkait perekrutan pegawai ini dapat dipertanggungjawabkan dan meminimalisir terjadinya perekrutan karyawan yang tidak sesuai dengan kriteria yang diinginkan perusahaan serta tidak kompeten. Salah satu metode dalam pengambilan keputusan yang dapat digunakan adalah Simple Additive Weighting (SAW) [2][5]. Konsep dasar dari metode SAW adalah untuk menemukan jumlah tertimbang dari peringkat kinerja pada setiap alternatif dan semua atribut yang memerlukan proses normalisasi matriks keputusan ke skala yang sebanding dengan peringkat alternatif yang ada [1]. Metode SAW ini dipilih dikarenakan metode ini mampu untuk menyeleksi alternatif terbaik dari sejumlah alternatif yang ada berdasarkan kriteria yang spesifik [1], [3], [5], [6]. Selain itu, metode SAW merupakan metode yang cukup populer dan sering digunakan untuk pemecahan masalah yang melibatkan banyak atribut [7]-[9].

Pada beberapa penelitian yang membahas tentang perekrutan pegawai [2]-[6] memasukkan unsur hasil test terhadap pelamar sebagai kriteria dalam perekrutanya seperti penampilan, test, kedisiplinan, ketaatan, keterampilan, hasil kerja, perilaku, dll. disamping kriteria administratif. Sementara pada penelitian ini hanya difokuskan pada seleksi administrasi, sehingga kriteria yang digunakan hanya mengarah pada kriteria administratif seperti pendidikan terakhir, pengalaman, usia, status perkawinan, jurusan dan nilai yang diambil dari IPK jika pelamar adalah lulusan Diploma atau Sarjana dan Nilai Ijazah jika pelamar merupakan lulusan SMA sederajat. Adapun kriteria pendidikan terakhir dan usia juga digunakan oleh penelitian [4], [5], serta pengalaman dan status perkawinan digunakan oleh penelitian [4] sebagai beberapa kriteria yang digunakan untuk melakukan rekrutmen pegawai. Sementara itu, penelitian ini menambahkan jurusan dan nilai sebagai kriteria yang digunakan dalam pengambilan keputusan rekrutmen karyawan.

Selain itu, beberapa sub kriteria pada penelitian [3], [4], [6] ini lebih bersifat subjektif dengan menempatkan indikator seperti "sangat baik", "baik" "cukup", sementara pada penelitian ini, rentang nilai pada sub kriteria dibuat lebih jelas mengarah pada satu nilai tertentu, sehingga dapat meminimalisir unsur subjektifitas saat menentukan rating kecocokan dari setiap alternatif untuk setiap kriteria yang dimaksud.

Pada penelitian ini akan dilakukan pencarian nilai bobot untuk setiap kriteria kemudian dilakukan pemeringkatan alternatif yang paling optimal dengan metode SAW, sehingga terpilih calon karyawan terbaik yang memiliki kualifikasi paling sesuai dengan kriteria yang dicari oleh 
perusahaan saat melakukan perekrutan.

\section{METODE PENELITIAN}

Adapun metode yang dilakukan dalam penelitian ini terdiri dari studi pustaka, observasi dan wawancara.

a) Studi Pustaka; dilakukan dalam penelitian ini dengan mempelajari buku, jurnal ilmiah maupun artikel yang relevan dengan permasalahan yang dibahas. Dalam hal ini permasalahan yang dimaksud dalah terkait seleksi/ rekrutmen pegawai di suatu perusahaan dengan menggunakan salah satu metode pengambilan keputusan, yakni Simple Additive Weighting (SAW).

b) Observasi; dilakukan dengan melakukan pengamatan dan peninjauan langsung ke objek yang akan di teliti dalam hal ini adalah PT. ABC, guna mencari data yang relevan terkait dengan permasalahan yang dangkat, yakni seleksi/ rekrutmen pegawai dengan menerapkan metode pengambilan keputusan Simple Additive Weighting (SAW) di suatu perusahaan agar penelitian ini menghasilkan informasi yang akurat.

c) Wawancara; dilakukan kepada pihak-pihak yang terkait dengan seleksi/ rekrutmen pegawai di suatu perusahaan secara langsung. Dalam hal ini, wawancara dilakukan dengan staff dan manager HRD guna mengetahui informasi-informasi yang dibutuhkan, terutama terkait kriteria yang dimiliki oleh perusahaan dalam melakukan proses rekrutmen pegawai agar penerapan metode Simple Additive Weighting (SAW) memperoleh urutan alternatif terbaik, yakni terpilihnya calon karyawan terbaik dari sekian banyak calon karyawan yang melamar diperusahaan tersebut.

\subsection{Metode Pengambilan Keputusan}

Keputusan merupakan aktifitas atau kegiatan memilih satu dari sekumpulan alternatif yang diambil untuk menjadi solusi dari sebuah permasalahan, dimana keputusan yang diambil untuk memecahkan sebuah permasalahan tersebut dapat dilihat dari jenisnya, yakni keputusan terstruktur, semi terstruktur dan tidak terstruktur [1].

Salah satu metode yang digunakan dalam pengambilan keputusan adalah Simple Additive Weighting (SAW). Metode SAW dikenal dengan istilah metode penjumlahan terbobot dengan konsep dasarnya mencari penjumlahan terbobot dari rating kinerja pada setiap alternatif pada semua atribut [1], [4], [10], [11]. Menurut Simon, terdapat tiga fase utama dalam proses pengambilan keputusan, yaitu fase Inteligensi (intelligence), desain (design) dan pemilihan (choice). Kemudian Ia menambahkan fase keempat yakni implementasi (implementation) [10], [12], [13]. Gambar keempat fase dalam proses pengambilan keputusan dapat dilihat pada Gambar 1.
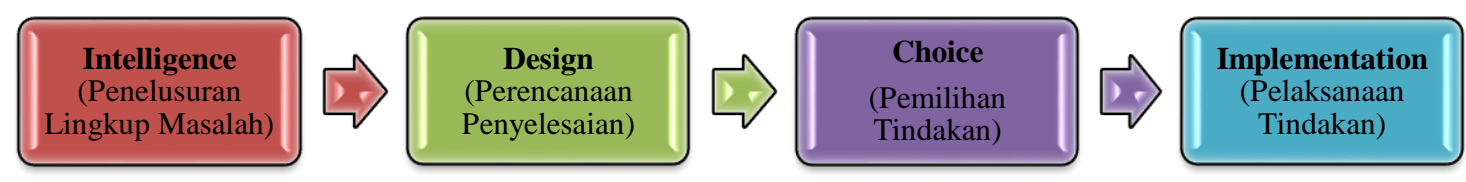

Gambar 1 Fase Proses Pengambilan Keputusan

Adapun langkah-langkah penyelesaian menggunakan metode Simple Additive Weighting (SAW) adalah sebagai berikut [8], [11], [14]:

1. Menentukan kriteria-kriteria yang akan dijadikan acuan dalam pengambilan keputusan, yaitu $(C i)$.

2. Menentukan rating kecocokan setiap alternatif pada setiap kriteria.

3. Membuat matriks keputusan berdasarkan kriteria $(C i)$, kemudian melakukan normalisasi matriks berdasarkan persamaan yang sesuai dengan jenis atribut (atribut keuntungan (benefit) atau atribut biaya (cost) sehingga diperoleh matriks ternormalisasi R. Adapun rumus yang digunakan untuk melakukan normalisasi mariks seperti Persamaan 1. 


$$
r i j=\left\{\begin{array}{lr}
\frac{x i j}{\max ^{(x i j)}} & \text { Jika } j \text { adalah atribut keuntungan (benefit) } \\
\frac{\min ^{(x i j)}}{x i j} & \text { Jika j adalah atribut biaya (cost) }
\end{array}\right.
$$

Keterangan:

$r i j=$ Rating kinerja ternormalisasi

$x i j=$ Baris dan kolom dari matriks

$\max (x i j)=$ Nilai maksimum dari setiap baris dan kolom

$\min (x i j)=$ Nilai minimum dari setiap baris dan kolom

4. Hasil akhir diperoleh dari proses perankingan yaitu penjumlahan dari perkalian matriks ternormalisasi $\mathrm{R}$ dengan vektor bobot sehingga diperoleh nilai terbesar yang dipilih sebagai alternatif terbaik $(A i)$ sebagai solusi. Nilai rij adalah rating kinerja ternormalisasi dari alternatif $A i$ pada atribut $C i=1,2, .$, m dan $j=1,2, . .$, m. Nilai preferensi untuk setiap alternatif $(V i)$ diberikan sebagai rumus pada Persamaan 2 berikut.

$$
V i=\sum_{j=1}^{n} W_{j} r_{i j}
$$

Keterangan:

$V i=$ Nilai akhir dari alternatif

$W j=$ Bobot yang telah ditentukan

$R i j=$ Normalisasi matriks

$\min (x i j)=$ Nilai minimum dari setiap baris dan kolom

Nilai $V i$ yang lebih besar mengindikasikan bahwa alternatif $A i$ lebih terpilih.

Setelah diperoleh hasil akhir dari proses perankingan, maka pimpinan perusahaan akan membandingkan dengan standar nilai yang dimiliki oleh perusahaan (dalam hal ini standar nilai yang ditetapkan yakni 70) agar calon karyawan dapat meneruskan proses rekrutmen selanjutnya, yakni test wawancara oleh pimpinan yang lebih tinggi.

\section{HASIL DAN PEMBAHASAN}

Berdasarkan hasil pengamatan dan peninjauan langsung ke objek penelitian yakni PT. $\mathrm{ABC}$, diperoleh data-data yang diperlukan untuk perhitungan menggunakan metode Simple Additive Weighting (SAW) yang terdiri dari data alternatif, kriteria hingga sub kriteria yang selanjutnya dapat diteruskan menjadi proses perhitungan dan perangkingan hingga menghasilkan nilai akhir sebagai keputusan/ solusi dari permasalahan subjektifitas pada perekrutan pegawai, terutama dalam hal seleksi administrasi untuk menemukan calon pegawai yang paling memenuhi kriteria administratif yang telah ditentukan oleh perusahaan. Adapun proses penyelesaiannya adalah sebagai berikut:

\subsection{Menentukan Kriteria}

Menentukan nilai kriteria $(\mathrm{C} i)$ pada suatu set alternatif $(\mathrm{Ai})$ beserta bobot preferensi $(\mathrm{Wj})$ untuk setiap kriteria $(\mathrm{Ci})$. Adapun kriteria $(\mathrm{Ci})$ dan bobot preferensi $(\mathrm{Wj})$ setiap kriteria dapat dilihat pada Tabel 1. Sementara itu, pembobotan untuk masing-masing subkriteria dijabarkan pada Tabel 2 dan alternatif keputusan pada objek penelitian dapat dilihat pada Tabel 3. 
Tabel 1 Kriteria

\begin{tabular}{|c|c|c|c|}
\hline Kriteria (Ci) & Keterangan & Jenis & Bobot $(\mathbf{W j )}$ \\
\hline C1 & Pendidikan Terakhir & Benefit & 0,19 \\
\hline C2 & Jurusan & Benefit & 0,21 \\
\hline C3 & Nilai & Benefit & 0,17 \\
\hline C4 & Pengalaman & Benefit & 0,17 \\
\hline C5 & Usia & Cost & 0,14 \\
\hline C6 & Status Perkawinan & Cost & 0,12 \\
\hline
\end{tabular}

Tabel 2 Bobot Kriteria Pendidikan

\begin{tabular}{|c|c|c|c|c|c|c|}
\hline \multirow{2}{*}{$\begin{array}{l}\text { Kriteria } \\
\quad(\mathrm{Ci})\end{array}$} & \multirow{2}{*}{\multicolumn{2}{|c|}{ Keterangan }} & \multicolumn{4}{|c|}{ Bobot $(W j)$} \\
\hline & & & 1 & $\mathbf{0 , 7 5}$ & $\mathbf{0 , 5 0}$ & $\mathbf{0 , 2 5}$ \\
\hline $\mathrm{C} 1$ & \multicolumn{2}{|r|}{ Pendidikan Terakhir } & Minimal S1 & Diploma 3 & $\begin{array}{c}\text { Diploma } 1- \\
\text { Diploma } 2 \\
\end{array}$ & $\begin{array}{c}\text { SMA/ SMK } \\
\text { Sederajat }\end{array}$ \\
\hline $\mathrm{C} 2$ & \multicolumn{2}{|r|}{ Jurusan } & $\begin{array}{l}\text { Akuntansi } \\
\text { (AK) }\end{array}$ & $\begin{array}{c}\text { Manajemen } \\
(\mathrm{MJ})\end{array}$ & $\begin{array}{c}\text { Komputerisasi } \\
\text { Akuntansi (KA) }\end{array}$ & $\begin{array}{c}\text { Selain AK, MJ } \\
\text { dan KA }\end{array}$ \\
\hline \multirow{2}{*}{$\mathrm{C} 3$} & \multirow{2}{*}{ Nilai } & IPK & $3,60-4,00$ & $3,20-3,59$ & $2,80-3,19$ & $2,50-2,79$ \\
\hline & & Rata-Rata Nilai Ijazah & $\geq 8,5$ & $8,2-8,4$ & $7,8-8,1$ & $7,5-7,7$ \\
\hline $\mathrm{C} 4$ & \multicolumn{2}{|r|}{ Pengalaman } & $\geq 4$ & $2-3$ Tahun & 1 Tahun & $\begin{array}{c}\text { Tidak } \\
\text { Berpengalaman } \\
\end{array}$ \\
\hline $\mathrm{C} 5$ & & Usia & $\geq 32$ Tahun & $28-31$ Tahun & $24-27$ Tahun & 18 - 23 Tahun \\
\hline C6 & & Status Perkawinan & Kawin & - & - & Belum Kawin \\
\hline
\end{tabular}

Tabel 3 Alternatif

\begin{tabular}{|c|c|c|c|c|c|c|c|}
\hline $\begin{array}{c}\text { Alternatif } \\
(\boldsymbol{A} \boldsymbol{i})\end{array}$ & Nama & $\begin{array}{c}\text { Pendidikan } \\
\text { Terakhir }\end{array}$ & Jurusan & Nilai & Pengalaman & Usia & Status Perkawinan \\
\hline A1 & Vivi Arianti & S1 & Akuntansi & 3,2 & Tidak Ada & 23 & Belum Kawin \\
\hline A2 & Cecilia Dwi & D3 & Akuntansi & 2,8 & 1 Tahun & 24 & Belum Kawin \\
\hline A3 & Vera Wijaya & D3 & Manajemen & 3,62 & Tidak Ada & 24 & Belum Kawin \\
\hline A4 & $\begin{array}{c}\text { Lisna } \\
\text { Aprilianti }\end{array}$ & SMA & IPS & 7,6 & 1 Tahun & 19 & Belum Kawin \\
\hline A5 & Adi Kusuma & S1 & Sistem Informasi & 2,76 & Tidak Ada & 23 & Belum Kawin \\
\hline A6 & David Yap & SMA & IPA & 7,5 & Tidak Ada & 19 & Belum Kawin \\
\hline A7 & Fredy Rico & SMK & Akuntansi & 7,7 & Tidak Ada & 20 & Belum Kawin \\
\hline A8 & Ika Dwi A. & S1 & Akuntansi & 3,4 & Tidak Ada & 24 & Belum Kawin \\
\hline A9 & Rani Lestari & S1 & Akuntansi & 3,57 & Tidak Ada & 24 & Belum Kawin \\
\hline A10 & Tomi & SMA & IPS & 7,6 & 1 Tahun & 22 & Belum Kawin \\
\hline
\end{tabular}

\subsection{Menentukan Rating Kecocokan}

Setelah diketahui alternatif yang ada, kemudian dipetakan rating kecocokan dari setiap alternatif pada setiap kriteria. Adapun hasil nya dapat dilihat pada Tabel 4.

Tabel 4 Rating Kecocokan Setiap Alternatif

\begin{tabular}{|c|c|c|c|c|c|c|}
\hline Alternatif $(\mathbf{A i})$ & C1 & C2 & C3 & C4 & C5 & C6 \\
\hline A1 & 1 & 1 & 0,75 & 0,25 & 0,25 & 0,25 \\
\hline A2 & 0,75 & 1 & 0,5 & 0,5 & 0,5 & 0,25 \\
\hline A3 & 0,75 & 0,75 & 1 & 0,25 & 0,5 & 0,25 \\
\hline A4 & 0,25 & 0,25 & 0,25 & 0,5 & 0,25 & 0,25 \\
\hline A5 & 1 & 0,25 & 0,25 & 0,25 & 0,25 & 0,25 \\
\hline A6 & 0,25 & 0,25 & 0,25 & 0,25 & 0,25 & 0,25 \\
\hline A7 & 0,25 & 1 & 0,25 & 0,25 & 0,25 & 0,25 \\
\hline A8 & 1 & 1 & 0,75 & 0,25 & 0,5 & 0,25 \\
\hline A9 & 1 & 1 & 0,75 & 0,25 & 0,5 & 0,25 \\
\hline A10 & 0,25 & 0,25 & 0,25 & 0,5 & 0,25 & 0,25 \\
\hline
\end{tabular}

\subsection{Normalisasi Matriks Keputusan}

Hasil dari rating kecocokan pada Tabel 4, dapat dibentuk sebuah matriks untuk keputusan $(X)$ sebagai berikut: 


$X=\left[\begin{array}{cccccc}1 & 1 & 0,75 & 0,25 & 0,25 & 0,25 \\ 0,75 & 1 & 0,5 & 0,5 & 0,5 & 0,25 \\ 0,75 & 0,75 & 1 & 0,25 & 0,5 & 0,25 \\ 0,25 & 0,25 & 0,25 & 0,5 & 0,25 & 0,25 \\ 1 & 0,25 & 0,25 & 0,25 & 0,25 & 0,25 \\ 0,25 & 0,25 & 0,25 & 0,25 & 0,25 & 0,25 \\ 0,25 & 1 & 0,25 & 0,25 & 0,25 & 0,25 \\ 1 & 1 & 0,75 & 0,25 & 0,5 & 0,25 \\ 1 & 1 & 0,75 & 0,25 & 0,5 & 0,25 \\ 0,25 & 0,25 & 0,25 & 0,5 & 0,25 & 0,25\end{array}\right]$

Dari matriks $(X)$ tersebut, kemudian dilakukan normalisasi matriks dengan mengimplementasikan Persamaan 1 dengan memilih salah satu persamaan yang sesuai dengan jenis atributnya, baik itu atribut keuntungan (benefit) maupun atribut biaya (cost) untuk menghasilkan matriks yang ternormalisasi (Matriks R). Adapun proses normalisasi untuk menghitung nilai masing-masing kriteria adalah sebagai berikut:

1. Kriteria Pendidikan (C1), merupakan atribut keuntungan (benefit)

$$
\begin{aligned}
& r 11=\frac{1}{\operatorname{Max}\{1 ; 0,75 ; 0,75 ; 0,25 ; 1 ; 0,25 ; 0,25 ; 1 ; 1 ; 0,25\}}=\frac{1}{1}=1 \\
& r 21=\frac{0,75}{\operatorname{Max}\{1 ; 0,75 ; 0,75 ; 0,25 ; 1 ; 0,25 ; 0,25 ; 1 ; 1 ; 0,25\}}=\frac{0,75}{1}=0,75
\end{aligned}
$$$$
r 31=\frac{0,75}{\operatorname{Max}\{1 ; 0,75 ; 0,75 ; 0,25 ; 1 ; 0,25 ; 0,25 ; 1 ; 1 ; 0,25\}}=\frac{0,75}{1}=0,75
$$$$
r 41=\frac{0,25}{\operatorname{Max}\{1 ; 0,75 ; 0,75 ; 0,25 ; 1 ; 0,25 ; 0,25 ; 1 ; 1 ; 0,25\}}=\frac{0,25}{1}=0,25
$$$$
r 51=\frac{1}{\operatorname{Max}\{1 ; 0,75 ; 0,75 ; 0,25 ; 1 ; 0,25 ; 0,25 ; 1 ; 1 ; 0,25\}}=\frac{1}{1}=1
$$$$
r 61=\frac{0,25}{\operatorname{Max}\{1 ; 0,75 ; 0,75 ; 0,25 ; 1 ; 0,25 ; 0,25 ; 1 ; 1 ; 0,25\}}=\frac{0,25}{1}=0,25
$$$$
r 71=\frac{0,25}{\operatorname{Max}\{1 ; 0,75 ; 0,75 ; 0,25 ; 1 ; 0,25 ; 0,25 ; 1 ; 1 ; 0,25\}}=\frac{0,25}{1}=0,25
$$$$
r 81=\frac{1}{\operatorname{Max}\{1 ; 0,75 ; 0,75 ; 0,25 ; 1 ; 0,25 ; 0,25 ; 1 ; 1 ; 0,25\}}=\frac{1}{1}=1
$$

$$
r 91=\frac{1}{\operatorname{Max}\{1 ; 0,75 ; 0,75 ; 0,25 ; 1 ; 0,25 ; 0,25 ; 1 ; 1 ; 0,25\}}=\frac{1}{1}=1
$$

$$
r 101=\frac{0,25}{\operatorname{Max}\{1 ; 0,75 ; 0,75 ; 0,25 ; 1 ; 0,25 ; 0,25 ; 1 ; 1 ; 0,25\}}=\frac{0,25}{1}=0,25
$$

2. Kriteria Jurusan (C2), merupakan atribut keuntungan (benefit)

$$
\begin{aligned}
& r 12=\frac{1}{\operatorname{Max}\{1 ; 1 ; 0,75 ; 0,25 ; 0,25 ; 0,25 ; 1 ; 1 ; 1 ; 0,25\}}=\frac{1}{1}=1 \\
& r 22=\frac{1}{\operatorname{Max}\{1 ; 1 ; 0,75 ; 0,25 ; 0,25 ; 0,25 ; 1 ; 1 ; 1 ; 0,25\}}=\frac{1}{1}=1 \\
& r 32=\frac{0,75}{\operatorname{Max}\{1 ; 1 ; 0,75 ; 0,25 ; 0,25 ; 0,25 ; 1 ; 1 ; 1 ; 0,25\}}=\frac{0,75}{1}=0,75
\end{aligned}
$$


$r 42=\frac{0,25}{\operatorname{Max}\{1 ; 1 ; 0,75 ; 0,25 ; 0,25 ; 0,25 ; 1 ; 1 ; 1 ; 0,25\}}=\frac{0,25}{1}=0,25$

$r 52=\frac{0,25}{\operatorname{Max}\{1 ; 1 ; 0,75 ; 0,25 ; 0,25 ; 0,25 ; 1 ; 1 ; 1 ; 0,25\}}=\frac{0,25}{1}=0,25$

$r 62=\frac{0,25}{\operatorname{Max}\{1 ; 1 ; 0,75 ; 0,25 ; 0,25 ; 0,25 ; 1 ; 1 ; 1 ; 0,25\}}=\frac{0,25}{1}=0,25$

$r 72=\frac{1}{\operatorname{Max}\{1 ; 1 ; 0,75 ; 0,25 ; 0,25 ; 0,25 ; 1 ; 1 ; 1 ; 0,25\}}=\frac{1}{1}=1$

$r 82=\frac{1}{\operatorname{Max}\{1 ; 1 ; 0,75 ; 0,25 ; 0,25 ; 0,25 ; 1 ; 1 ; 1 ; 0,25\}}=\frac{1}{1}=1$

$r 92=\frac{1}{\operatorname{Max}\{1 ; 1 ; 0,75 ; 0,25 ; 0,25 ; 0,25 ; 1 ; 1 ; 1 ; 0,25\}}=\frac{1}{1}=1$

$r 102=\frac{0,25}{\operatorname{Max}\{1 ; 1 ; 0,75 ; 0,25 ; 0,25 ; 0,25 ; 1 ; 1 ; 1 ; 0,25\}}=\frac{0,25}{1}=0,25$

3. Kriteria Nilai (C3), merupakan atribut keuntungan (benefit)

$r 13=\frac{0,75}{\operatorname{Max}\{0,75 ; 0,5 ; 1 ; 0,25 ; 0,25 ; 0,25 ; 0,25 ; 0,75 ; 0,75 ; 025\}}=\frac{0,75}{1}=0,75$

$r 23=\frac{0,5}{\operatorname{Max}\{0,75 ; 0,5 ; 1 ; 0,25 ; 0,25 ; 0,25 ; 0,25 ; 0,75 ; 0,75 ; 025\}}=\frac{0,5}{1}=0,5$

$r 33=\frac{1}{\operatorname{Max}\{0,75 ; 0,5 ; 1 ; 0,25 ; 0,25 ; 0,25 ; 0,25 ; 0,75 ; 0,75 ; 025\}}=\frac{1}{1}=1$

$r 43=\frac{0,25}{\operatorname{Max}\{0,75 ; 0,5 ; 1 ; 0,25 ; 0,25 ; 0,25 ; 0,25 ; 0,75 ; 0,75 ; 025\}}=\frac{0,25}{1}=0,25$

$r 53=\frac{0,25}{\operatorname{Max}\{0,75 ; 0,5 ; 1 ; 0,25 ; 0,25 ; 0,25 ; 0,25 ; 0,75 ; 0,75 ; 025\}}=\frac{0,25}{1}=0,25$

$r 63=\frac{0,25}{\operatorname{Max}\{0,75 ; 0,5 ; 1 ; 0,25 ; 0,25 ; 0,25 ; 0,25 ; 0,75 ; 0,75 ; 025\}}=\frac{0,25}{1}=0,25$

$r 73=\frac{0,25}{\operatorname{Max}\{0,75 ; 0,5 ; 1 ; 0,25 ; 0,25 ; 0,25 ; 0,25 ; 0,75 ; 0,75 ; 025\}}=\frac{0,25}{1}=0,25$

$r 83=\frac{0,75}{\operatorname{Max}\{0,75 ; 0,5 ; 1 ; 0,25 ; 0,25 ; 0,25 ; 0,25 ; 0,75 ; 0,75 ; 025\}}=\frac{0,75}{1}=0,75$

$r 93=\frac{0,75}{\operatorname{Max}\{0,75 ; 0,5 ; 1 ; 0,25 ; 0,25 ; 0,25 ; 0,25 ; 0,75 ; 0,75 ; 025\}}=\frac{0,75}{1}=0,75$

$r 103=\frac{0,25}{\operatorname{Max}\{0,75 ; 0,5 ; 1 ; 0,25 ; 0,25 ; 0,25 ; 0,25 ; 0,75 ; 0,75 ; 025\}}=\frac{0,25}{1}=0,25$

4. Kriteria Pengalaman (C4), merupakan atribut keuntungan (benefit)

$$
\begin{aligned}
& r 14=\frac{0,25}{\operatorname{Max}\{0,25 ; 0,5 ; 0,25 ; 0,5 ; 0,25 ; 0,25 ; 0,25 ; 0,25 ; 0,25 ; 0,5\}}=\frac{0,25}{0,5}=0,5 \\
& r 24=\frac{0,5}{\operatorname{Max}\{0,25 ; 0,5 ; 0,25 ; 0,5 ; 0,25 ; 0,25 ; 0,25 ; 0,25 ; 0,25 ; 0,5\}}=\frac{0,5}{0,5}=1 \\
& r 34=\frac{0,25}{\operatorname{Max}\{0,25 ; 0,5 ; 0,25 ; 0,5 ; 0,25 ; 0,25 ; 0,25 ; 0,25 ; 0,25 ; 0,5\}}=\frac{0,25}{0,5}=0,5 \\
& r 44=\frac{0,5}{\operatorname{Max}\{0,25 ; 0,5 ; 0,25 ; 0,5 ; 0,25 ; 0,25 ; 0,25 ; 0,25 ; 0,25 ; 0,5\}}=\frac{0,5}{0,5}=1
\end{aligned}
$$




$$
\begin{aligned}
& r 54=\frac{0,25}{\operatorname{Max}\{0,25 ; 0,5 ; 0,25 ; 0,5 ; 0,25 ; 0,25 ; 0,25 ; 0,25 ; 0,25 ; 0,5\}}=\frac{0,25}{0,5}=0,5 \\
& r 64=\frac{0,25}{\operatorname{Max}\{0,25 ; 0,5 ; 0,25 ; 0,5 ; 0,25 ; 0,25 ; 0,25 ; 0,25 ; 0,25 ; 0,5\}}=\frac{0,25}{0,5}=0,5 \\
& r 74=\frac{0,25}{\operatorname{Max}\{0,25 ; 0,5 ; 0,25 ; 0,5 ; 0,25 ; 0,25 ; 0,25 ; 0,25 ; 0,25 ; 0,5\}}=\frac{0,25}{0,5}=0,5 \\
& r 84=\frac{0,25}{\operatorname{Max}\{0,25 ; 0,5 ; 0,25 ; 0,5 ; 0,25 ; 0,25 ; 0,25 ; 0,25 ; 0,25 ; 0,5\}}=\frac{0,25}{0,5}=0,5 \\
& r 94=\frac{0,25}{\operatorname{Max}\{0,25 ; 0,5 ; 0,25 ; 0,5 ; 0,25 ; 0,25 ; 0,25 ; 0,25 ; 0,25 ; 0,5\}}=\frac{0,25}{0,5}=0,5 \\
& r 104=\frac{0,5}{\operatorname{Max}\{0,25 ; 0,5 ; 0,25 ; 0,5 ; 0,25 ; 0,25 ; 0,25 ; 0,25 ; 0,25 ; 0,5\}}=\frac{0,5}{0,5}=1
\end{aligned}
$$

\section{Kriteria Usia (C5), merupakan atribut biaya (cost)}

6.

$$
\begin{aligned}
& r 15=\frac{\operatorname{Min}\{0,25 ; 0,5 ; 0,5 ; 0,25 ; 0,25 ; 0,25 ; 0,25 ; 0,5 ; 0,5 ; 0,25\}}{0,25}=\frac{0,25}{0,25}=1 \\
& r 25=\frac{\operatorname{Min}\{0,25 ; 0,5 ; 0,5 ; 0,25 ; 0,25 ; 0,25 ; 0,25 ; 0,5 ; 0,5 ; 0,25\}}{0,5}=\frac{0,25}{0,5}=0,5 \\
& r 35=\frac{\operatorname{Min}\{0,25 ; 0,5 ; 0,5 ; 0,25 ; 0,25 ; 0,25 ; 0,25 ; 0,5 ; 0,5 ; 0,25\}}{0,5}=\frac{0,25}{0,5}=0,5 \\
& r 45=\frac{\operatorname{Min}\{0,25 ; 0,5 ; 0,5 ; 0,25 ; 0,25 ; 0,25 ; 0,25 ; 0,5 ; 0,5 ; 0,25\}}{0,25}=\frac{0,25}{0,25}=1 \\
& r 55=\frac{\operatorname{Min}\{0,25 ; 0,5 ; 0,5 ; 0,25 ; 0,25 ; 0,25 ; 0,25 ; 0,5 ; 0,5 ; 0,25\}}{0,25}=\frac{0,25}{0,25}=1 \\
& r 65=\frac{\operatorname{Min}\{0,25 ; 0,5 ; 0,5 ; 0,25 ; 0,25 ; 0,25 ; 0,25 ; 0,5 ; 0,5 ; 0,25\}}{0,25}=\frac{0,25}{0,25}=1 \\
& r 75=\frac{\operatorname{Min}\{0,25 ; 0,5 ; 0,5 ; 0,25 ; 0,25 ; 0,25 ; 0,25 ; 0,5 ; 0,5 ; 0,25\}}{0,25}=\frac{0,25}{0,25}=1 \\
& r 85=\frac{\operatorname{Min}\{0,25 ; 0,5 ; 0,5 ; 0,25 ; 0,25 ; 0,25 ; 0,25 ; 0,5 ; 0,5 ; 0,25\}}{0,5}=\frac{0,25}{0,5}=0,5 \\
& r 95=\frac{\operatorname{Min}\{0,25 ; 0,5 ; 0,5 ; 0,25 ; 0,25 ; 0,25 ; 0,25 ; 0,5 ; 0,5 ; 0,25\}}{0,5}=\frac{0,25}{0,5}=0,5 \\
& r 105=\frac{\operatorname{Min}\{0,25 ; 0,5 ; 0,5 ; 0,25 ; 0,25 ; 0,25 ; 0,25 ; 0,5 ; 0,5 ; 0,25\}}{0,25}=\frac{0,25}{0,25}=1
\end{aligned}
$$

7. Kriteria Status Perkawinan (C6), merupakan atribut biaya (cost) $r 16=\frac{\operatorname{Min}\{0,25 ; 0,25 ; 0,25 ; 0,25 ; 0,25 ; 0,25 ; 0,25 ; 0,25 ; 0,25 ; 0,25 ;}{0,25}=\frac{0,25}{0,25}=1$
$r 26=\frac{\operatorname{Min}\{0,25 ; 0,25 ; 0,25 ; 0,25 ; 0,25 ; 0,25 ; 0,25 ; 0,25 ; 0,25 ; 0,25 ;\}}{0,25}=\frac{0,25}{0,25}=1$
$r 36=\frac{\operatorname{Min}\{0,25 ; 0,25 ; 0,25 ; 0,25 ; 0,25 ; 0,25 ; 0,25 ; 0,25 ; 0,25 ; 0,25 ;\}}{0,25}=\frac{0,25}{0,25}=1$
$r 46=\frac{\operatorname{Min}\{0,25 ; 0,25 ; 0,25 ; 0,25 ; 0,25 ; 0,25 ; 0,25 ; 0,25 ; 0,25 ; 0,25 ;\}}{0,25}=\frac{0,25}{0,25}=1$
$r 56=\frac{\operatorname{Min}\{0,25 ; 0,25 ; 0,25 ; 0,25 ; 0,25 ; 0,25 ; 0,25 ; 0,25 ; 0,25 ; 0,25 ;\}}{0,25}=\frac{0,25}{0,25}=1$
$r 66=\frac{\operatorname{Min}\{0,25 ; 0,25 ; 0,25 ; 0,25 ; 0,25 ; 0,25 ; 0,25 ; 0,25 ; 0,25 ; 0,25 ;\}}{0,25}=\frac{0,25}{0,25}=1$ 


$$
\begin{aligned}
& r 76=\frac{\operatorname{Min}\{0,25 ; 0,25 ; 0,25 ; 0,25 ; 0,25 ; 0,25 ; 0,25 ; 0,25 ; 0,25 ; 0,25 ;\}}{0,25}=\frac{0,25}{0,25}=1 \\
& r 86=\frac{\operatorname{Min}\{0,25 ; 0,25 ; 0,25 ; 0,25 ; 0,25 ; 0,25 ; 0,25 ; 0,25 ; 0,25 ; 0,25 ;\}}{0,25}=\frac{0,25}{0,25}=1 \\
& r 96=\frac{\operatorname{Min}\{0,25 ; 0,25 ; 0,25 ; 0,25 ; 0,25 ; 0,25 ; 0,25 ; 0,25 ; 0,25 ; 0,25 ;\}}{0,25}=\frac{0,25}{0,25}=1 \\
& r 106=\frac{\operatorname{Min}\{0,25 ; 0,25 ; 0,25 ; 0,25 ; 0,25 ; 0,25 ; 0,25 ; 0,25 ; 0,25 ; 0,25 ;\}}{0,25}=\frac{0,25}{0,25}=1
\end{aligned}
$$

Hasil dari normalisasi matriks tersebut dibentuk menjadi sebuah matriks yang ternormalisasi (matriks R) sebagai berikut:

$$
R=\left[\begin{array}{cccccc}
1 & 1 & 0,75 & 0,5 & 1 & 1 \\
0,75 & 1 & 0,5 & 1 & 0,5 & 1 \\
0,75 & 0,75 & 1 & 0,5 & 0,5 & 1 \\
0,25 & 0,25 & 0,25 & 1 & 1 & 1 \\
1 & 0,25 & 0,25 & 0,5 & 1 & 1 \\
0,25 & 0,25 & 0,25 & 0,5 & 1 & 1 \\
0,25 & 1 & 0,25 & 0,5 & 1 & 1 \\
1 & 1 & 0,75 & 0,5 & 0,5 & 1 \\
1 & 1 & 0,75 & 0,5 & 0,5 & 1 \\
0,25 & 0,25 & 0,25 & 1 & 1 & 1
\end{array}\right]
$$

\subsection{Proses Perangkingan Alternatif}

Setelah didapatkan matriks yang ternormalisasi, maka selanjutnya dilakukan proses perangkingan menggunakan bobot yang telah ditentukan oleh pengambil keputusan dengan mengimplementasikan Persamaan 2 untuk memperoleh alternatif terbaik sebagai solusi dari permasalahan perekrutan karyawan. Adapun pengimplementasian Persamaan 2 adalah sebagai berikut:

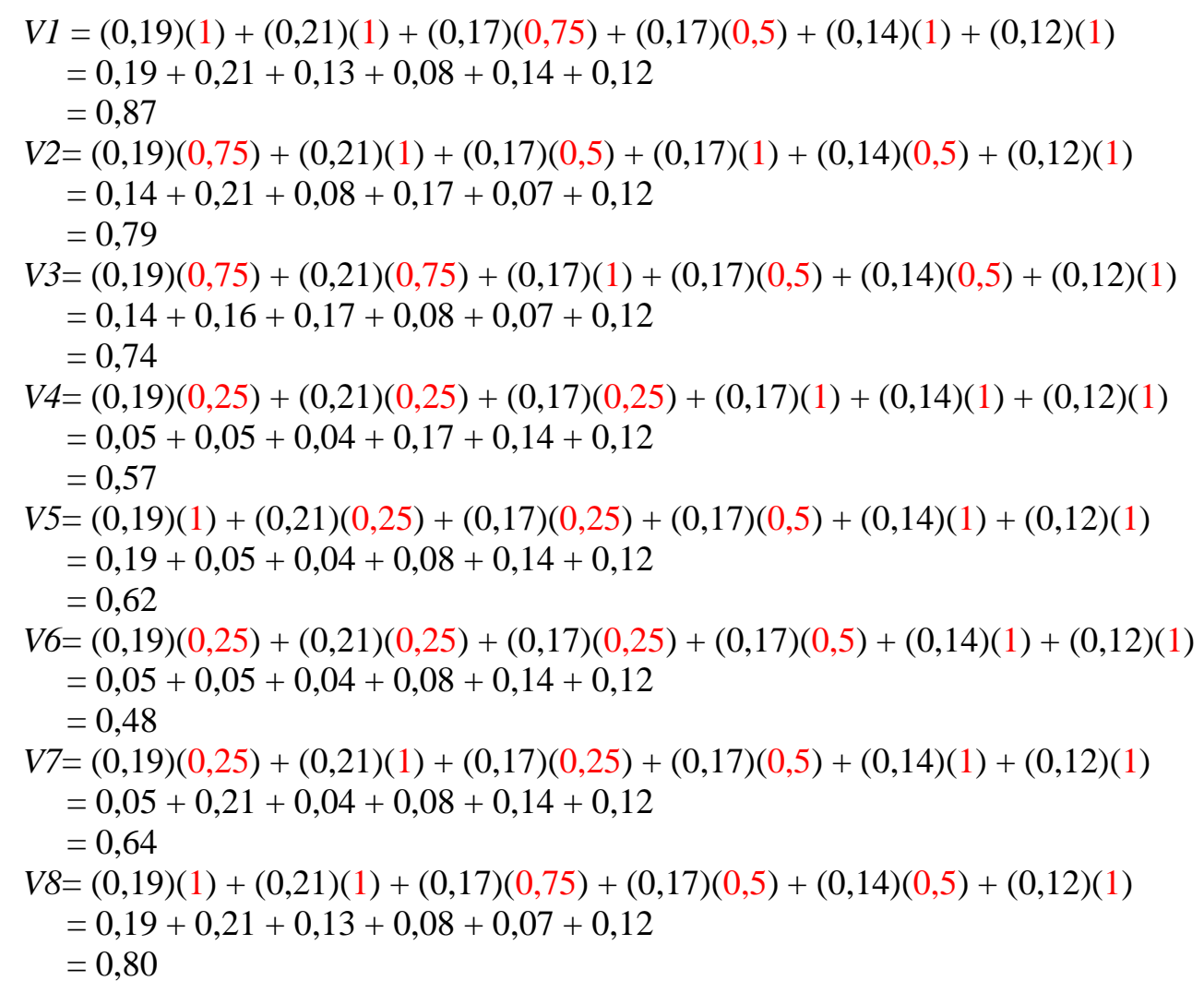




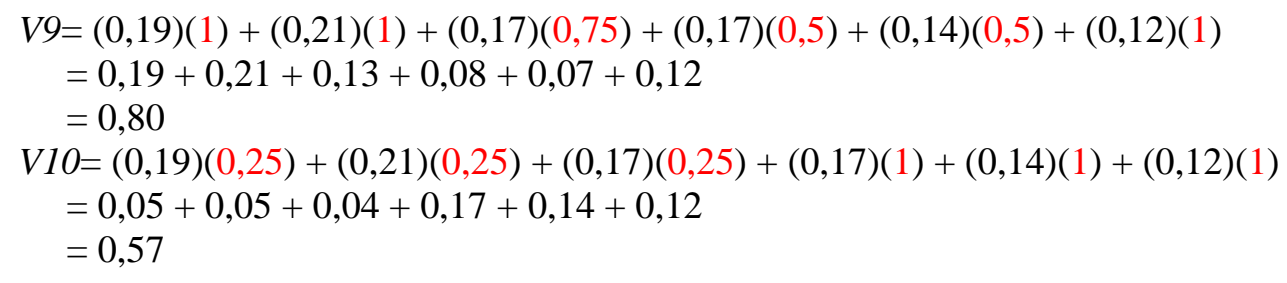

Dari hasil implementasi Persamaan 2 diatas, maka diperoleh hasil yang kemudian diurutkan dari jumlah terbesar hingga terkecil seperti yang terlihat pada Tabel 5 .

Tabel 5 Kriteria

\begin{tabular}{|c|c|c|}
\hline Alternatif & Nama & Nilai Akhir Alternatif (Vi) \\
\hline A1 & Vivi Arianti & 0,87 \\
\hline A8 & Ika Dwi A & 0,80 \\
\hline A9 & Rani Lestari & 0,80 \\
\hline A2 & Cecilia Dwi & 0,79 \\
\hline A3 & Vera Wijaya & 0,74 \\
\hline A7 & Fredy Rico & 0,64 \\
\hline A5 & Adi Kusuma & 0,62 \\
\hline A4 & Lisna Aprilianti & 0,57 \\
\hline A10 & Tomi & 0,57 \\
\hline A6 & David Yap & 0,48 \\
\hline
\end{tabular}

Pada Tabel 5 dapat dilihat bahwa, jika perusahaan memiliki standar minimal 70\% $(0,70)$ agar calon karyawan dapat meneruskan proses rekrutmen selanjutnya, yakni test wawancara oleh pimpinan yang lebih tinggi, maka perusahaan hanya perlu mewawancarai 5 (lima) dari 10 (sepuluh) calon pelamar yang memiliki nilai akhir sesuai standar perusahaan, yakni Vivi Arianti (A1), Ika Dwi A (A8), Rani Lestari (A9), Cecilia Dwi (A2) serta Vera Wijaya (A3). Hal ini tentu dapat meminimalisir waktu wawancara serta kesalahan seleksi secara administratif.

\section{KESIMPULAN DAN SARAN}

4.1 Kesimpulan berikut:

Berdasarkan penelitian yang telah dilakukan, maka diperoleh kesimpulan sebagai

1. Metode Simple Additive Weighting (SAW) dapat digunakan untuk membantu perusahaan, khususnya bagian HRD di PT. ABC dalam proses rekrutmen pegawai secara objektif, cepat dan akurat karena mampu melakukan perangkingan terhadap sejumlah alternatif dengan beragam kriteria penilaian.

2. Hasil perhitungan yang dihasilkan dari penerapan Metode Simple Additive Weighting (SAW) ini dapat dijadikan acuan bagi bagian HRD di PT. ABC untuk menentukan calon pegawai yang lolos dalam proses seleksi administrasi dan berhak untuk menempuh proses selanjutnya dalam tahapan rekrutmen pegawai, yakni proses wawancara oleh pimpinan.

\subsection{Saran}

Adapun saran yang dapat diberikan bagi penelitian selanjutnya, adapun saran yang dapat diberikan adalah:

1. Metode Simple Additive Weighting (SAW) dalam rekrutmen pegawai ini dapat dilanjutkan dengan mengakomodir proses seleksi wawancara yang dilakukan oleh pimpinan yang lebih tinggi, mengingat dalam proses wawancara juga biasanya terdapat beberapa kriteria yang harus dinilai.

2. Penerapan metode Simple Additive Weighting (SAW) dapat digunakan dalam pembuatan Sistem Pendukung Keputusan (SPK) agar bagian HRD di PT. ABC dapat memperoleh hasil perangkingan alternatif dengan lebih cepat dan tetap akurat. 


\section{DAFTAR PUSTAKA}

[1] N. Setiawan et al., "Simple Additive Weighting as Decision Support System for Determining Employees Salary," Int. J. Eng. Technol., vol. 7, no. 2.14 Special Issue 14, 2018.

[2] A. Afshari, M. Mojahed, and R. Yusuff, "Simple additive weighting approach to personnel selection problem," Int. J. Innov. Manag. Technol., vol. 1, no. 5, pp. 511-515, 2010.

[3] S. S. Sundari and Y. F. Taufik, "Sistem Pendukung Keputusan Penerimaan Pegawai Baru Dengan Menggunakan Metode Simple Additive Weighting (SAW)," Sisfotenika, vol. Vol. 4, No, pp. 140-151, 2014.

[4] E. Ismanto and N. Effendi, "Sistem Pendukung Keputusan Penerimaan Karyawan Dengan Metode Simple Additive Weighting (SAW)," SATIN - Sains dan Teknol. Inf., vol. 3, no. 1, p. 1, 2017.

[5] A. Faizin and E. Mulyanto, "Penerapan Metode Simple Additive Weighting (SAW) Untuk Seleksi Tenaga Kerja Baru Bagian Produksi (Studi Kasus Pada PT . Jesi Jason Surja Wibowo )," Univ. Dian Nuswantoro Semarang, pp. 1-9, 2015.

[6] Y. Djamain and H. De Christin, "Sistem Pendukung Keputusan Penerimaan Pegawai Baru PT. PLN (Persero) Kantor Pusat Dengan Menggunakan Metode Simple Additive Weighting (SAW)," J. Tek. Inform., vol. 8, no. 1, pp. 39-47, 2015.

[7] A. Setyawan, F. Y. Arini, and I. Akhlis, "Comparative Analysis of Simple Additive Weighting Method and Weighted Product Method to New Employee Recruitment Decision Support System (DSS) at PT. Warta Media Nusantara," Sci. J. Informatics, vol. 4, no. 1, pp. 34-42, 2017.

[8] A. Wanto and H. Damanik, "Analisis Penerapan Sistem Pendukung Keputusan Terhadap Seleksi Penerima Beasiswa BBM (Bantuan Belajar Mahasiswa) Pada Perguruan Tinggi Menggunakan Metode Simple Additive Weighting (SAW) (Studi Kasus: AMIK Tunas Bangsa Pematangsiantar)," Pros. Semin. Nas. Rekayasa II, vol. 2, no. November, pp. 323-333, 2015.

[9] W. Deni, O. Sudana, and A. Sasmita, "Analysis and Implementation Fuzzy MultiAttribute Decision Making SAW Method for Selection of High Achieving Students in Faculty Level," Int. J. Comput. Sci. Issues, vol. 10, no. 1, pp. 674-680, 2013.

[10] D. Nofriansyah, Konsep Data Mining VS Sistem Pendukung Keputusan. Medan: Deepublish (CV Budi Utama), 2014.

[11] H. T. Sigit and D. A. Permana, "Sistem Pendukung Keputusan Pemilihan Mobil LCGC Menggunakan Simple Additive Weighting," J. Sist. Inf., vol. Volume 4, 2017.

[12] M. Marbun and B. Sinaga, Buku Ajar Sistem Pendukung Keputusan Penilaian Hasil Belajar dengan Metode Topsis, no. April. Medan: CV. Rudang Mayang, 2018.

[13] Kusrini, Konsep dan Aplikasi Sistem Pendukung Keputusan, 1st ed. Yogyakarta: Andi Offset, 2007.

[14] J. A. J. L. Batu and C. Fibriani, "Analisis Penentuan Lokasi Evakuasi Bencana Banjir dengan Pemanfaatan Sistem Informasi Geografis Dan Metode Simple Additive Weighting (Studi Kasus : Kota Surakarta)," J. Teknol. Inf. dan Ilmu Komput., vol. 4, no. 2, pp. 127-135, 2017. 